\title{
Low-Cost Data Acquisition Station for Microclimate Detection and Public Health Risks Management: A Case Study of Casablanca
}

\author{
https://doi.org/10.3991/ijoe.v16i05.13049 \\ Akensous Youness ${ }^{(凶)}$, Hakdaoui Mustapha, \\ Al-Akad Sultan, Al Sabri Ahmed \\ Hassan II University, Casablanca, Morocco \\ akensous1990@gmail.com
}

\begin{abstract}
The environmental data acquisition station is used to manage the public health and detection of a microclimate of a city for a broadcast processed high precision data for users. This research article is summarizing the applications of Electronics and GIS applications to health risks management due to air pollution, noise and microclimate change detection, to study the geography of urban health risks and environmental change in Casablanca, Morocco. acquisition of environmental and Climatological Data using sensor networks, results a new possibilities and advantages, of environmental data monitoring using electronic circuit with a broadcasting system via a technology with wireless transmitter. The main object of this research is to present a simple and rapid method to provide instant microclimate and environment data, which can be used to manage the public risks caused by pollution and environment changes. As the climate and environment conditions are variable from a place to place, it is difficult to get accurate climate and environment for a particular location in a city. With the advancement of technology, especially data acquisition systems, the problem of large set up area and cost has been reduced. The data acquisition station can be set up at any place and provide an accurate and instant climate and environment report to any citizen of the city. The report of the data acquisition system can be used by the users to choose the best place for them to live due to their diseases. In addition, these data can be collected in a GIS system to create a microclimate change and air pollution map of different zones in the city, predict the future climate, and air pollution of the city.
\end{abstract}

Keywords-Microclimate, public health risk, electronic circuit, risk management.

\section{Introduction}

In previous years, the urban evolution of cities, the intrusion and the violation of ecosystems have caused many unhealthy phenomena such as climate change, air pollution, as well as the infection of the general environment of the cities (the quality of life of the citizens) [4][11]. In a megalopolis city the climate change from time to time, 
place to place drastically, similarly for the quantity of particulates hazardous fine particles present in the air such as carbon, monoxide, methane, propane also the noise [18][10]. Which can easily occur in megalopolises like the biggest city in Morocco (Casablanca). In addition, there are no specific devices currently located and implemented in Casablanca city to provide and democratize access of real-time microclimate data and air pollution also noise data. The modern system on data acquisition is advanced of technology. The data acquisition station uses miniaturized measuring instrument, efficient, reliable to provide instant microclimate, air pollution, and noise data.

The air pollution is a global concern as it may cause many chronic and fatal risks and disease. Especially in developing countries, rapid urbanization is happening, without paying attention to the environment [8][9][12][19]. As urban areas have high density of population, maintaining air quality is becoming more and more challenging. People are unknowingly exposed to harmful gases making them prone to many deadly diseases. The effect is even more severe for young and elder adults. Road vehicles and industrial units are one of the main sources of outdoor air pollution in cities. Currently, atmospheric pollutant concentrations are collected by environmental or governmental authorities using fixed monitoring station, equipped with instruments specialized in the measurement of many pollutants, such as carbon monoxide (co), oxides of nitro-gen (nox), and sulfur. Carbon dioxide (so2), ozone (o3) and particulate matter [1][2][3][7]. One of the threats that affect the public health of city inhabitants is noise pollution who's been increasing and is not taken into account for most inhabitants of the city of Casablanca. It has been estimated that around $90 \%$ of Casablanca city suffer from noise.

The main object of this work is providing the microclimate, air pollution and noise daily data. The air pollution and noise data, can affect our daily lives and health, if we didn't know about them in right time we would be in serious trouble. Air quality, noise and microclimate detection is based on a low-cost sensing, who will reduce initial investments and annual operating costs for example in Europe, all countries are required to comply with the EU Directives (e.g. the Council Directive 96/62/EC on ambient air quality assessment and management, commonly referred to as the Air Quality Framework Directive). Such directive describes the basic principles for assessing and managing air quality in the Member States, and list the pollutants for which air quality standards and objectives shall be developed and specified in the legislation. These also recommend specific numbers of monitoring stations for individual pollutants, on the basis of the number of inhabitants and geographic partitioning.

The data acquisition station is a set of sensors connected to an electronic circuit that processes and analyzes the data in order to transmit the data to the user via a wireless model [15][16][17]. Data acquisition station can continuously perform data acquisition, event detection, environment monitoring. Because the station can wirelessly send and receive data, data acquisition stations are used in man applications.it can be widely used in environmental monitoring, industrial production, air pollution monitoring, smart cities, and other fields [20]. With the advent of the Internet of Things era, they are increasingly applied extensively, and they have gradually penetrated into all areas of human life and have attracted the attention of people in the industry. At the end Modern data acquisition is the processes of measuring real world physical conditions captured as analog waveforms and converted into digital numeric values that can be manipulated 
by a computer [5][6][13][14][21][22]. Multiple parameters are multiplexed and finally proceeding through a single channel to the computer to show the data. For Broadcasting, the data taken by the sensors are transmitted to users near the station via WIRELESS or sent via GPRS to a server then consulted on the web interface as maps.

\section{Motivation and Purpose}

Today, monitoring the environment and the microclimate is becoming one of the challenging tasks. Getting the accurate data of the environment and microclimate of a city, then democratizing access to this category of data by broadcasting it by Wi-Fi to any user close to the station is the main aim of this work. Knowing that the public health of the inhabitants of the city is strongly affected by pollution and climatic conditions, hence the importance of making these data available to the inhabitants.

\subsection{Justification of the project}

For microclimate detection: The climatological stations installed in Casablanca does not provide data on the micro climate of the city of Casablanca, since it is the largest city in Morocco, hence the importance of acquiring micro climate data is paramount. Thus, it will be used to prevent and manage environmental risks in relation to climate and pollution.

For public health risks: The relationship between public health and the environment is increasing. The importance of acquiring the data in relation to the latter is very primary like the quality of the air (pollution), the noise, the humidity the data acquisition station proposed in this work will allow users to know the ideal place to preserve their health, or the citizen can avoid residing in high risk areas de-pending on their diseases.

\subsection{Lack of monitoring systems in Casablanca}

In Casablanca, the lack of a survey conducts to observe the various air quality and weather parameters through analog devices give as a point on doing this work. The topic of weather, air pollution monitoring is not new. However, a monitoring station broadcasting data for inhabitants near to this one without using network is rare. Most of the previous works have shown a complicated hardware system and different devices were made for the analysis of different parameters. Many research papers about weather monitoring have been published over the last years, but we are not aware of any specifically showing a new idea that can help inhabitants to know the general condition as well as air quality and weather on a real time by getting it directly from the monitoring station without having internet, especially for developing country like Morocco.

Monitoring weather, health quality change seems to be a major challenge in todays for a megalopolis. Casablanca is affected by those changes because it's the industrial city in Morocco. The increasing number of populations, climate and pollution changes from a localization to another are all posing potential barriers on public health. The 
public health degradation occurs in a long time and it is not easy to stop it, but we can reduce the risks by applying cheap available technologies. The weather change and degradation of the public health continue to affect social welfare of citizens, since there is no easy way to send data to inhabitants. Every day, weather, environment quality affects our people in their daily-life. The effect of those changes can be managed by applying today's new technology.

\section{System Overview}

The concept of the system is based on an Arduino module which reads the data from the sensors, and the GPS and sends this data via WIFI to a connected device (Fig. 1). The connected device is a smartphone running an application that receives this information, to display it on the screen, with the possibility of storing it in memory. The system also sends this data to the server for display in the form of a map via a geographic information system (Fig. 2).

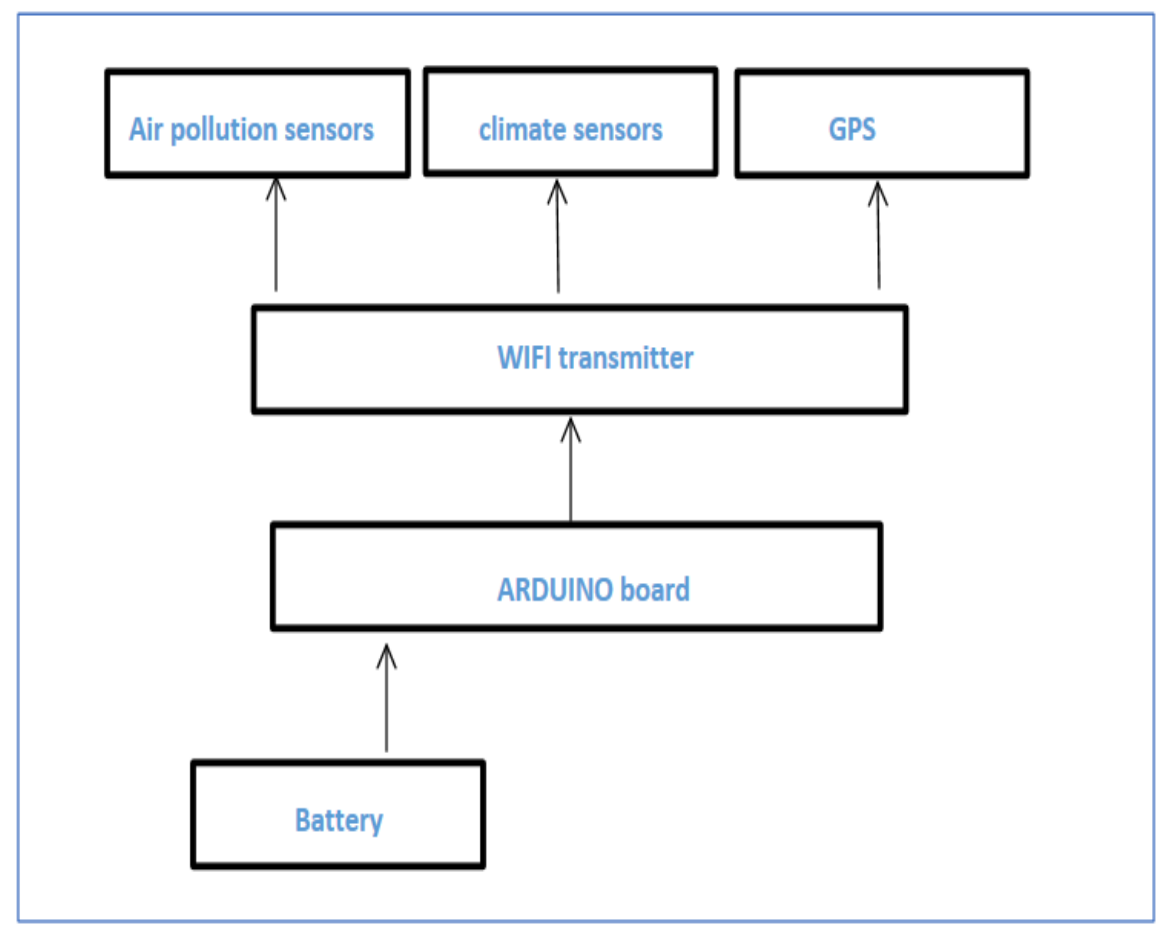

Fig. 1. Station System. 


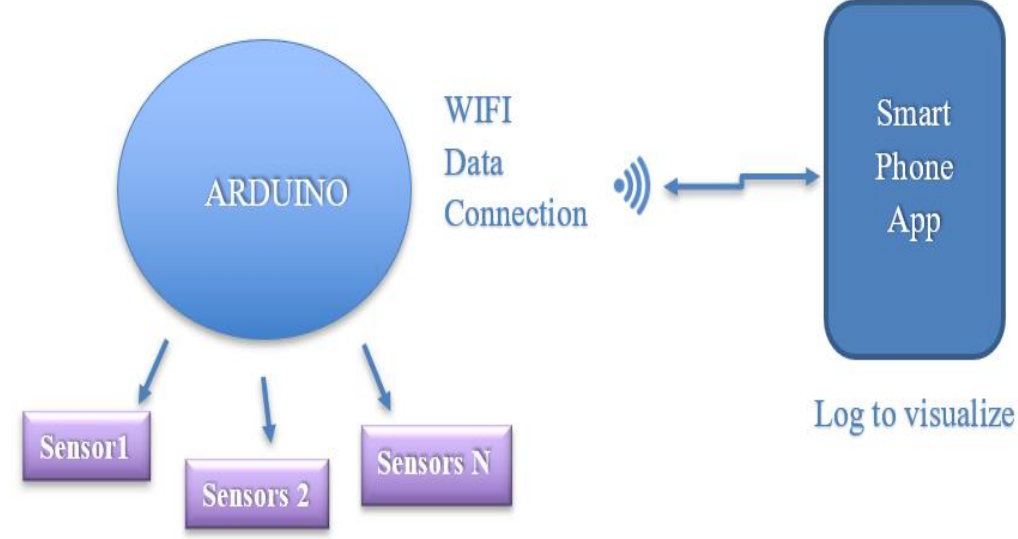

Fig. 2. Station System.

\section{$4 \quad$ Result and Discussion}

The data, controlling unit is an embedded system platform. Here an Arduino is used. It is powered by a battery or solar panel power \& programmed for the specific applications using Arduino open source software. The sensors and GPS, collect data and send it to the Arduino for digitally processing analysis of data. A transmitter-receiver Wi-Fi module is also connected with the system for wireless data transmission. All the modules will be set in a cube box of small dimension. The station can be placed anywhere.

The Architecture of the station is shown in Fig. 3 which is comprised of three parts first one is the primary processing tasks are done by the Arduino microcontroller; the second is the tasks related to network communication are run through the WIFI Module; and the third is the Sensors and GPS, which provides data to the Arduino.

The Arduino divided into different subsections:

- Main: Manages the overall tasks based on the inputs received from the different components, triggers reading, publishing and stocking data collected by sensors and GPS, communication with the WIFI module.

- Power: Manages battery power, and battery charging.

- Configuration: Takes charge of the configuration on the station.

The WIFI module manages network related tasks. It communicates with the Arduino and takes care of tasks like, publishing data to the cloud, setting up an access point through a web interface.

The Sensor and GPS: offers data to the Arduino as like temperature, humidity, etc. and the position by GPS when the station will be in move. 


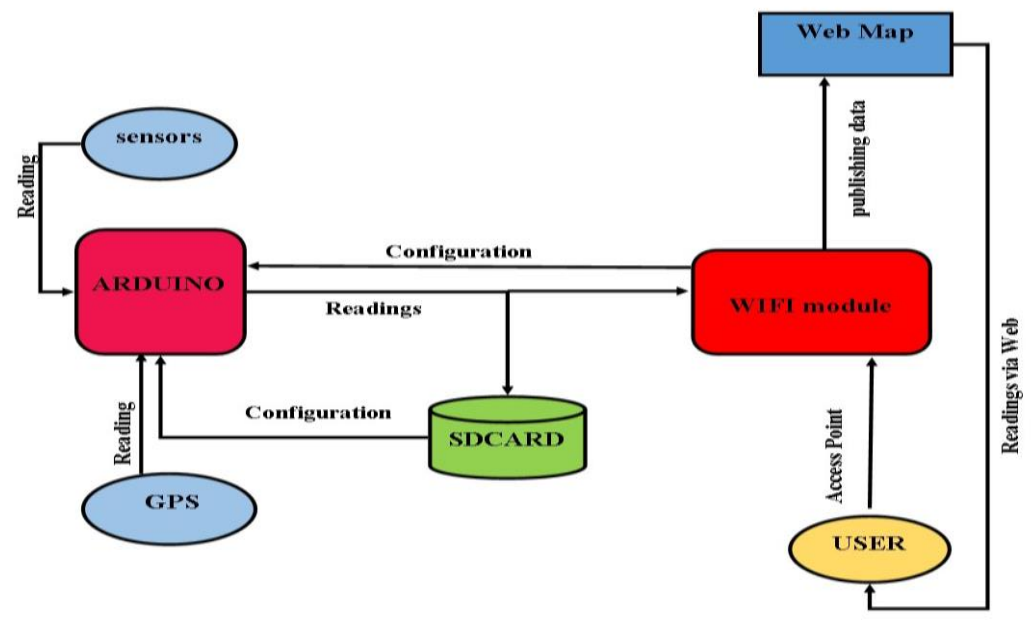

Fig. 3. Station Architecture.

\subsection{Hardware system}

The circuit diagram of the station is (shown in Fig. 4) a prototype which we will built in our lab then will be deployed in real world scenario which is connected via Wi-Fi to the users (smartphones) next to it and also send data to the cloud.

Though it is evident that more sensors we will be using, the more accurate data we will get so, to build the device, we have used important primary sensors (Humidity/Temperature, Gas, Noise, Rain and Carbon monoxide) which are connected to the Arduino board.

With these sensors connected to an Arduino, this prototype is connected via Wi-Fi to obtain data that enable the user to know the environment and the appropriate place for Human Heath.

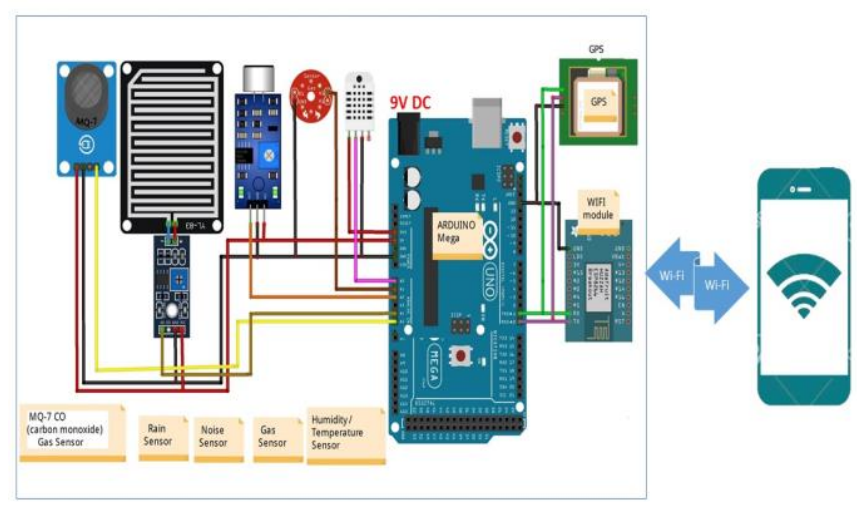

Fig. 4. Diagram of the Complete System. 


\subsection{Public health risk management related to the urban environment}

The acquisition stations data must be consulted by municipalities and scientists throughout the cloud. From this data, regional and local response plan according to the risks incurred can be established. In this area, Geomatics is an indispensable tool for assessing impact zones by type of risk depending on their location and the severity indexes in each location. Organizations can identify planning and response methods for public health emergencies. Delineate the areas exposed to risks, known as "danger zones", taking into account the nature and intensity of the risk incurred. Delineate the so-called "precautionary zones", which are not directly exposed to risks. Define prevention, protection and safeguard measures to be taken in the areas mentioned.

\subsection{Developing a culture of risk among citizens}

Whatever measures are taken to limit the intensity of the risk, the effectiveness of the long-term prevention policy requires training and information for citizens, which enable them to adopt responsible behavior with full knowledge of the facts. To do this, the identification of high-risk areas must be systematic and widely communicated to the public. In all areas concerned, the population must be informed of the risks it faces. It must be aware of the lack of human control over environmental risks, the relative effectiveness of solutions and the need to accept the constraints of its environment. In dangerous areas, it must practice proper behavior for its protection.

\subsection{The challenges}

New technological developments in environmental sensing bring along, as expected, some techno-economic challenges. The most significant of these is the reliability of measured data, since most sensors require independent evaluation under a range of ambient environmental conditions [4]. Further challenges include improving the sensors' typically short working time, as well as their robustness, through rigorous evaluation under a range of diverse environmental conditions. Economic challenges include reducing maintenance (including calibration, solar panel power maintenance) and data management/analysis/visualization costs, which in many cases exceed the cost of the actual sensor system itself. Finally, new challenges lie ahead if the decision makers are not prepared to embrace such technology, especially in non-developed country like Morocco, knowing that our target is the municipal agencies as customers. The main technological challenge regarding the use of sensors for environment and weather monitoring is to improve their sensitivity, stability and longevity of operation before replacement. Measurements from distributed sensors can be transmitted at almost real-time and stored in databases, and online platforms can be a means for dissemination but in such location where there's no internet the direct transmission of data by wireless (WiFi) provide an excellent means for fast and transparent dissemination. Ownership and dissemination of the monitored data provide both challenges and opportunities. This should be addressed effectively and transparently, to benefit the public and help the authorities in health quality and weather management. Data management centers should 
be established, where data would be stored, validated, processed and modelled into formats which are useful to various stakeholders, such as visual spatiotemporal maps, or predictions of concentrations and exposures related to pollution and noise, emission patterns and meteorological forecasts.

\section{Conclusion}

We have designed a station for climate and environment monitoring system. The station can be a provider of data that will be exploited by Geomatic science to have a good urban risk management. The system is simple to construct, portable, cost efficient, less power consuming and reliable. We demonstrate the hardware design and the data acquisition system. We have designed a station for climate and environment monitoring system. The system is simple to construct, portable, cost efficient, green power consuming and reliable. We demonstrate the hardware design and the data acquisition station. As the system does not use just internet network (direct transmission to near users), data transmission has low cost which in terms provides large applications. It will have a positive impact on the public health quality and help the authorities in the environment and weather management. There are some limitations such as the device may not communicate to a long distance without powerful transceivers section. The components may be damaged by long time use.

\section{References}

[1] Prashant Kumar, Lidia Morawska , Claudio Martani , George Biskos, Marina Neophytou,Silvana Di Sabatino, Margaret Bell, Leslie Norford, Rex Britter, The rise of low-cost sensing for managing air pollution in cities, Environment International 2015. https://doi. org/10.1016/j.envint.2014.11.019

[2] Mead, M.I.; Popoola, O.A.M.;Stewart, G.B.; Landshoff, P.; Calleja, M.; Hayes, M.; Baldovi, J.J.; McLeod, M.W.; Hodgson, T.F.; Dicks, J.; Lewis, A.; Cohen, J.; Baron, R.; Saffell, J.R.; Jones, R.L. The use of electrochemical sensors for monitoring urban air quality in low-cost, high-density networks. Atmos Environ. 70:186-203; 2013. https://doi.org/ 10.1016/j.atmosenv.2012.11.060

[3] White, R.M., Paprotny, I., Frederick, Doering, F., Cascio,W., Solomon, P., Gundel, L.A., 2012.Sensors and 'Apps' for community-based atmospheric monitoring. Air WasteManage. Assoc. 5, 36-40.

[4] Malaysia Natural Heritage. (2013). Belum-Temengor Rainforest Complex. Retrieved 29 January, 2013.

[5] Q. Wei, N. Jin, X. Lou, R. Ma and J. Xu, Software Design for Water Environment Remote Monitoring System Based on Mobile Devices,Applied Mechanics and Materials, 2011. https://doi.org/10.4028/www.scientific.net/amm.58-60.2027

[6] G. Irwin, J. Colandairaj, and W. Scanlon, "Understanding wireless networked control systems through simulation," Comput.Control Eng., 2005. https://doi.org/10.1049/cce:200 $\underline{50205}$ 
[7] N. Telagam, N. Kandasamy, N. Prasad G, and M. Nanjundan, "Smart Sensor Network Based High Quality Air Pollution Monitoring System Using Labview," Int. J. Online Eng. IJOE, vol. 13, no. 8, p. 79, Aug. 2017, https://doi.org/10.3991/ijoe.v13i08.7161.

[8] Kumar, P., Jain, S., Gurjar, B.R., Sharma, P., Khare, M., Morawska, L., Britter, R., 2013. Newdirections: can a "blue sky" return to Indian megacities? Atmos. Environ. 71,198-201. https://doi.org/10.1016/j.atmosenv.2013.01.055

[9] Heal, M.R., Kumar, P., Harrison, R.M., 2012. Particles, air quality, policy and health. Chem. Soc. Rev. 41, 6606-6630.

[10] Croxford, B., Penn, A., 1998. Siting considerations for urban pollution monitors. Atmos.Environ. 32, 1049-1057.Cuff, D., Hansen, M., Kang, J., 2008. Urban sensing: out of the woods. Commun. ACM 51,24-33. https://doi.org/10.1016/s1352-2310(97)00366-x

[11] M. Hong, "Key Technology of Electronic Nose Gas Recognizer Based on Wireless Sensor Networks," Int. J. Online Eng. IJOE, vol. 14, no. 10, p. 68, Oct. 2018, https://doi.org/10. 3991/ijoe.v14i10.9304.

[12] K. E. Percy and M. Ferretti, "Air pollution and forest health: Towardnew monitoring concepts," in Environmental Pollution, 2004, vol. 130, pp. 113-126. https://doi.org/10.1016/ j.envpol.2003.10.034

[13] A. Yoddumnern, R. Chaisricharoen, and T. Yooyativong, "A Smart WiFi Multi-Sensor Node for Fire Detection Mechanism Based on Social Network," Int. J. Online Eng. IJOE, vol. 14, no. 10, p. 4, Oct. 2018. https://doi.org/10.3991/ijoe.v14i10.8488.

[14] Kuang, Y. L, Sung, J.H and Wen, T.S (2013) Mobile Monitoring and Embedded Control System for Factory Environment.

[15] M. RahamanLaskar, R. Bhattacharjee, M. SauGiri and P. Bhattacharya, Weather Forecasting using Arduino Based Cube-Sat, IMCIP-2016.

[16] X. Zhang, Y. Zhao, W. Zhao, W. Xu, and W. Ji, “A Wireless Sensor Networks-based Intelligent System for Library Air Quality Monitoring," Int. J. Online Eng. IJOE, vol. 12, no. 11, p. 76, Nov. 2016, https://doi.org/10.3991/ijoe.v12i11.6227

[17] 01db Oper@, noise measurement and monitoring station; 2015. http://01db.acoemgroup.com/catalog/01dB-OPER-Noise-measurement-and-monitoringstation>.

[18] Larson Davis Model 831-NMS permanent noise monitoring system 2015. <http://www.larsondavis.com/Products/NoiseMonitoringSystems/PermanentNoiseMonitor ingSystem>.

[19] Joy Dutta, Chandreyee Chowdhury, Sarbani Roy, Asif Iqbal Middya, FirojGazi, Towards Smart City: Sensing Air Quality in City based on Opportunistic Crowd-sensing, 2017 ACM. ISBN 978-1-4503-4839-3. https://doi.org/10.1145/3007748.3018286

[20] K. K. Khedo, R. Perseedoss, and A. Mungur, "A Wireless Sensor Network Air Pollution Monitoring System,” Int. J. Wirel. Mob. Netw., vol. 2, no. 2, pp. 31-45, May 2010, doi: 10.5121/ijwmn.2010.2203. https://doi.org/10.5121/ijwmn.2010.2203

[21] AL Sabri Ahmed, Khazri Yassine, Moussetad Mohamed, Akensous Youness, Fahli Ahmed, AL Amoudi Mohamed" Remote-Controlled Laboratories of Experimental Physics: Measuring the Stiffness of a Spring." Int. J. TMLAI,vol. 5, no 4, 2017. https://doi.org/10. 14738/tmlai.54.3187

[22] Al Sabri Ahmed, Moussetad Mohamed, Akensous Youness, Khazri Yassine, Fahli Ahmed, Al Amoudi Mohamed Saeed" Create and develop remote labs for practical experiments" 2017 Joint International Conference on Information and Communication Technologies for Education and Training and InternationalConference on Computing in Arabic (ICCATICET).2017, Khartoum, Sudan. https://doi.org/10.1109/icca-ticet.2017.8095306 


\section{$7 \quad$ Authors}

Akensous Youness is a PhD student in Faculty of sciences Ben M'sik, Hassan II University Casablanca, Department of Geology, Morocco (akensous1990@ @mail.com)

Hakdaoui Mustapha is a professor of Geology in the Department of Geology, Laboratory of Applied Geology, Geomatics and Environment, Faculty of sciences Ben M'sik, Hassan II University, Casablanca, Morocco (hakdaoui@ gmail.com)

Al-Akad Sultan is a PhD student in Faculty of sciences Ben M'sik, Hassan II University Casablanca, Department of Geology, Morocco (su.sultan12@gmail.com)

Al Sabri Ahmed is a PhD student in Faculty of sciences Ben M'sik, Hassan II University Casablanca, Department of Physics, laboratory of engineering and materials, Morocco, (a.alsabri2011@gmail.com).

Article submitted 2020-01-06. Resubmitted 2020-02-14. Final acceptance 2020-02-17. Final version published as submitted by the authors. 